\title{
COMUNICAÇÃO
}

\section{DESCRIÇÃO DE UM DISPOSITIVO PARA COLETA, INFECÇÃO EXPERIMENTAL E MANUTENÇÃO DE FLEBOTOMÍNEOS ADULTOS (Lutzomyia, Psychodidae, Diptera)}

\author{
J. A. Vexenat, C. Cuba Cuba, A. C. Barreto e P. D. Marsden
}

$\mathrm{Na}$ investigação entomológica de vetores potenciais de Leishmania e estudos sobre infecção experimental é necessário contar-se com dispositivos simples e econômicos que permitam rendimento máximo, quando empregados em técnicas de captura, alimentação, infecção experimental e manutenção de insetos em laboratório.

$\mathrm{Na}$ presente comunicação, descreve-se um dispositivo que atende a múltiplas finalidades na investigação entomológica, prestando-se como:

a) Um capturador de sucção, de desenho e construção simples.

b) Um aparelho que permite alimentação e/ou infecção experimental de flebotomineos.

c) Um recipiente de manutenção e criação desses insetos.

\section{DESCRICCÃO DO DISPOSITIVO:}

a) Dispositivo de captura. A Figura 1 mostra o capturador e os elementos que o constitui. Os numeros e letras entre parênteses correspondem às respectivas peças do dispositivo.

O corpo principal (1) é constituido por um frasco plástico, transparente, utilizado em cultivo de células (Corning, $250 \mathrm{ml}$ ). Uma folha de papel de filtro é introduzida, enrolada, através da abertura do frasco e

Trabalho realizado com o auxilio financeiro do Conselho Nacional de Desenvolvimento Cientifico e Tecnológico (CNPq) 403690/82, U. S. Public Health Service AI $16282 \mathrm{e}$ Ministério da Saúde (SUCAM).

Faculdade de Ciências da Saúde - Núcleo de Medicina Tropical e Nutrição, Universidade de Brasília, DF, 70910 Brasilia, Brasil.

Recebido para publicação em 29/5/84. em seguida disposta de maneira a revestir a parede inferior do frasco. Dois orificios de $1,0 \mathrm{~cm}$ de diâmetro são abertos no fundo (2) e na parede lateral superior do frasco (3), possibilitando o encaixe de dois tubos plásticos, com o mesmo diâmetro dos orificios e com $5 \mathrm{~cm}$ de comprimento. A colagem pode ser feita com Araldite ou Silicone. $\mathrm{O}$ tubo $A$ serve como coletor de insetos, sugados durante a captura (Figura 4). $\mathrm{O}$ tubo de sucção $B$, que penetra $0,5 \mathrm{~cm}$ no interior do frasco, tem na sua extremidade interna uma tela de filó e em sua abertura para o exterior é adaptado um tubo de borracha de $60 \mathrm{~cm}$ de comprimento, por meio de um pequeno fragmento de pipeta plástica de $10 \mathrm{ml}$.

b) Dispositivo para alimentação e/ou infecção experimental. $\mathrm{O}$ mesmo artefato anteriormente descrito é facilmente adaptado para servir como dispositivo para alimentação de flebotomíneos em patas de hamster ou de outro animal de pequeno porte (Orizomys, Proechimys) com ou sem lesão. Para essa finalidade, retira-se o tubo de borracha e a tampa plástica do frasco e introduz-se a(s) pata(s) portadora(s) de lesão do animal, previamente anestesiado (Figura 2). Uma das vantagens é a transparência da parede do frasco que facilita a observação do processo de alimentação dos insetos, o que se efetua em aproximadamente 20 minutos para as espécies $L u$. longipalpis e $\mathrm{Lu}$. whitmani. É fácil, então, monitorar a observação documentando o número de insetos bem alimentados. A sobrevivência de fêmeas e machos que foi acompanhada durante um periodo de 8 dias foi de $65 \%$ e $15 \%$ respectivamente.

c) Dispositivo para criação e manutenção. À simples recolocação da tampa do frasco, depois de concluida a etapa anterior de alimentação, segue-se a aplicação de um algodào embebido em solução supersaturada de sacarose, através do tubo coletor (Figura 3). Isto converte o artefato em um recipiente de manutenção e criação dos insetos. Utilizando-se esse dispositivo foi possivel desenvolver duas gerações de Lu. whitmani e oito de Lu. longipalpis. O ciclo ovoadulto se completa em média de 40 dias, e a utilização 
Vexenat JA, Cuba CC, Barreto AC, Marsden PD. Descriçāo de um dispositivo para coleta, infecção experimental e manutençao de flebotomíneos adultos (Lutzomyia, Psychodidae, Diptera). Revista da Sociedade Brasileira de Medicina Tropical 17: 151-152, Jul-Set, 1984
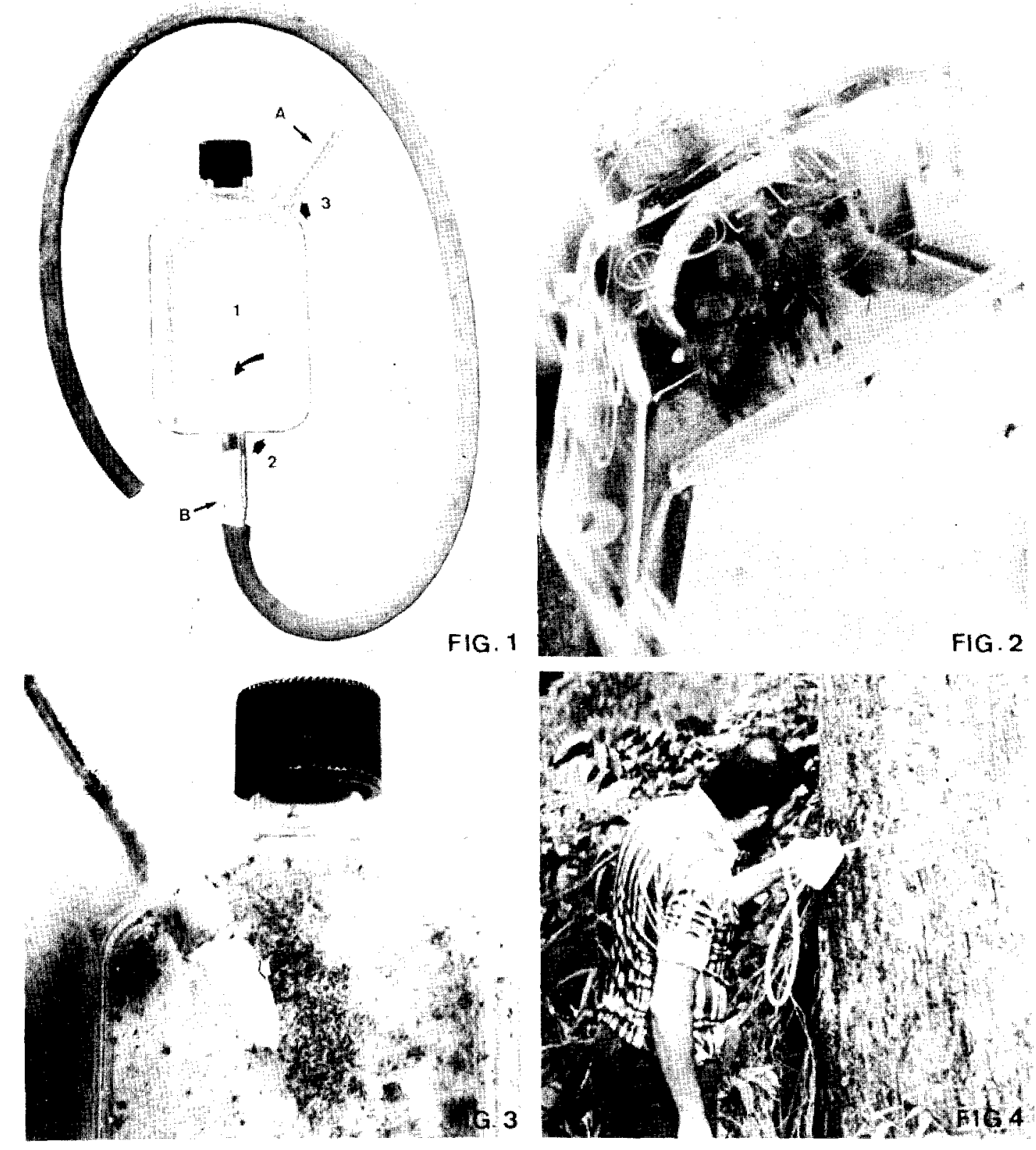

da dieta de Young e cols ${ }^{1}$ evita grandemente a contaminação por fungos.

Com esse dispositivo de simples construção é possivel coletar, alimentar e criar flebotomineos, além de permitir infecções experimentais desses insetos em lesões de pele de animais de pequeno porte.

\section{REFERENCIA BIBLIOGRÁFICA}

1 Young DG, Perkins PV, Endris RG. A larval diet for rearing phlebotomine sand flies (Diptera: Psychodidae). Department of Entomology and Nematology, University of Florida, Gainesville, Florida 32611, USA. 